\title{
Measurement-based Investigation of the DC and RF Transconductance for Various HEMT Technologies in High-and Low-temperature Conditions
}

Mohammad Abdul Alim ( $\square$ mohammadabdulalim@cu.ac.bd)

University of Chittagong https://orcid.org/0000-0002-3984-0176

Anwar Jarndal

University of Sharjah

Christophe Gaquiere

University of Lille: Universite de Lille

Giovanni Crupi

University of Messina: Universita degli Studi di Messina

\section{Research Article}

Keywords: GaAs, GaN, HEMT, multi-bias, multi-finger, multi-layer, pHEMT, scattering-parameter measurements, temperature, transconductance

Posted Date: July 29th, 2021

DOI: https://doi.org/10.21203/rs.3.rs-742793/v1

License: (9) This work is licensed under a Creative Commons Attribution 4.0 International License. Read Full License 


\title{
Measurement-based investigation of the DC and RF transconductance for various HEMT technologies in high-and low-temperature conditions
}

\author{
Mohammad Abdul Alim ${ }^{1 *}$, Anwar Jarndal2 ${ }^{2}$ Christophe Gaquiere ${ }^{3}$ and Giovanni Crupi ${ }^{4}$ \\ 1 Department of Electrical and Electronic Engineering, University of Chittagong, Chittagong 4331, Bangladesh; \\ mohammadabdulalim@cu.ac.bd \\ 2 Department of Electrical Engineering, University of Sharjah, Sharjah, 27272 Sharjah, UAE; ajarndal@sharjah.ac.ae \\ 3 Institute of Electronic, Microelectronic and Nanotechnology (IEMN), The University of Lille, F-59000 Lille, France; \\ christophe.gaquiere@iemn.univ-lille1.fr \\ 4 Department of Biomedical and Dental Sciences and Morphofunctional Imaging, University of Messina, Messina 98125, Italy; \\ crupig@unime.it \\ * Correspondence: mohammadabdulalim@cu.ac.bd
}

\begin{abstract}
The purpose of this experimental study is to evaluate quantitatively the impact of the temperature on the behavior of various high electron-mobility transistor (HEMT) technologies through the analysis of the DC and RF transconductance. The experimental data are reported for six different HEMT devices, in order to develop a comparative analysis based on various technologies, including gallium arsenide (GaAs) and gallium nitride (GaN) materials, matched and pseudomorphic HEMTs, single- (S-H) and double-heterojunction (D-H) HEMTs, and both virgin and multi-layer devices. The reported findings show that the impact of the ambient temperature on the HEMT behavior strongly depend on the tested technology and operating conditions. As a matter of fact, a higher temperature can lead to increased or degraded transconductance, depending on the device technologies and bias point. In the GaAs-based devices, an operating bias condition at which the DC and RF transconductance are temperature insensitive can be defined, owing to two-opposite temperature-dependent effects counteracting with each other.
\end{abstract}

Keywords: GaAs; GaN; HEMT; multi-bias; multi-finger, multi-layer; pHEMT; scattering-parameter measurements, temperature, transconductance

\section{Introduction}

The high electron-mobility transistor (HEMT) was introduced in the early 1980s [1, 2] and, over the years, has continuously evolved to meet the steadily increasing demanding requirements of the everexpanding microwave applications. The evolution of this type of transistor has been accomplished through the use of different materials, such as gallium arsenide (GaAs) and gallium nitride $(\mathrm{GaN})$, different structure designs, such as conventional lattice-matched HEMTs and pseudomorphic HEMTs (pHEMTs), multiple two-dimensional electron gas (2-DEG) channels, such as using a double heterojunction $(\mathrm{D}-\mathrm{H})$ rather than the conventional single heterojunction $(\mathrm{S}-\mathrm{H})$ in order to have two channels, different geometrical parameters, such as gate length $\left(L_{g}\right)$ and width $(W)$, and different operating conditions, such as bias point and frequency band. To improve device performance, HEMT devices are typically based on using the multi-finger layout, which consists of placing many gate fingers in parallel [3-5]. Therefore, the total gate width of multi-finger devices is given by the product of the number of fingers and their length. To develop highly integrated monolithic microwave integrated circuits (MMICs), HEMT devices might be realized using the multi-layer three-dimensional (3-D) technology [6-8]. 
Many studies have been devoted to the analysis of the temperature effects on the performance of the HEMT devices, focusing on both GaAs [9-18] and GaN [18-31] semiconductor technologies. The present article is aimed at an experimental investigation of the behavior of various HEMT technologies in highand low-temperature conditions. Six different HEMT devices are studied: $0.5 \mu \mathrm{m} \times(2 \times 100) \mu \mathrm{m} \mathrm{S}-\mathrm{H} \mathrm{GaAs}$ HEMT, $0.5 \mu \mathrm{m} \times(2 \times 75) \mu \mathrm{m}$ S-H GaAs HEMT, $0.5 \mu \mathrm{m} \times(2 \times 100) \mu \mathrm{m}$ virgin D-H GaAs pHEMT, $0.5 \mu \mathrm{m} \times$ $(2 \times 100) \mu \mathrm{m}$ multi-layer D-H GaAs pHEMT, $0.25 \mu \mathrm{m} \times(2 \times 100) \mu \mathrm{m}$ GaN HEMT, and $0.15 \mu \mathrm{m} \times(4 \times 50)$ $\mu \mathrm{m}$ GaN HEMT. The devices under test (DUTs) are characterized in terms of both DC and scattering (S-) parameter measurements at three different ambient temperatures $\left(\mathrm{T}_{\mathrm{a}}\right):-40^{\circ} \mathrm{C}, 25^{\circ} \mathrm{C}$, and $150^{\circ} \mathrm{C}$. The experimental data are used to investigate the effects of the temperature on the DC and RF values of the transconductance, which is a key figure of merit for determining low-noise and high-power performance of the HEMT devices that are widely used in the design of both low-noise [32-35] and high-power [35-38] amplifiers. The analysis is focused on the impact of the temperature on the DC transconductance $\left(\mathrm{g}_{\mathrm{m}}\right)$ that is determined from the measured DC transcharacteristics, the RF transconductance that is estimated as the real part of the measured short-circuit forward transfer admittance $\left(\mathrm{Y}_{21}\right)$ at low low-frequency, and the intrinsic RF transconductance ( $g_{\mathrm{mo}}$ ) of the small-signal equivalent-circuit model that is extracted from the S-parameter measurements. The experiments show that the temperature effects can strongly depend on the selected technology and bias condition. It should be underlined that in the four investigated GaAsbased devices there is an operating bias point at which the transconductance is temperature insensitive, the so called transconductance zero temperature coefficient (GZTC) point [17], whereas a significant degradation of the transconductance is observed for the two investigated GaN-based HEMTs at all studied values of the gate-source voltage.

The article is organized with the following sections. Section II describes the investigated devices and the experimental characterization, Section III reports and discusses the achieved experimental findings, and Section IV draws the main conclusions.

\section{Devices Under Test and Measurement Process}

Figure 1 shows the photographs of the six tested on-wafer devices: $0.5 \mu \mathrm{m} \times(2 \times 100) \mu \mathrm{m} \mathrm{S}-\mathrm{H} \mathrm{GaAs}$ HEMT, $0.5 \mu \mathrm{m} \times(2 \times 75) \mu \mathrm{m}$ S-H GaAs HEMT, $0.5 \mu \mathrm{m} \times(2 \times 100) \mu \mathrm{m}$ virgin D-H GaAs pHEMT, $0.5 \mu \mathrm{m} \times$ $(2 \times 100) \mu \mathrm{m}$ multi-layer D-H GaAs pHEMT, $0.25 \mu \mathrm{m} \times(2 \times 100) \mu \mathrm{m}$ GaN HEMT, and $0.15 \mu \mathrm{m} \times(4 \times 50)$ $\mu \mathrm{m}$ GaN HEMT.

The two S-H devices investigated in this work are AlGaAs/GaAs HEMTs grown by molecular beam epitaxy (MBE) on a 600- $\mu$ m-thick semi-insulating undoped GaAs substrate. Both devices have the same gate length of $0.5 \mu \mathrm{m}$ but differ in the gate widths, which are $200 \mu \mathrm{m}$ and $150 \mu \mathrm{m}$. The interdigitated layout of both devices is based on the parallel connection of two fingers but the two devices differ in the finger length: $100 \mu \mathrm{m}$ and $75 \mu \mathrm{m}$. Further fabrication details of these two S-H GaAs HEMTs can be found elsewhere [39].

The two investigated D-H pHEMTs are based on using the lattice mismatched AlGaAs/InGaAs/GaAs system grown by MBE on a $600-\mu$ m-thick semi-insulating undoped GaAs substrate. The two devices have a gate length of $0.5 \mu \mathrm{m}$ and a gate width of $200 \mu \mathrm{m}$. The interdigitated layout consists of two fingers, each being 100- $\mu \mathrm{m}$ long. These two pHEMTs differ only because one of the two devices is made utilizing the multi-layer 3-D MMIC technology. The complete MMIC integration method consists of opening a $\mathrm{Si}_{3} \mathrm{~N}_{4}$ window using buffered oxide etch (HF, hydrofluoric acid) and lithography on a wafer containing pre-fabricated pHEMTs and other passive components in a vertical plane. On top of the pre-fabricated pHEMTs, a conductor layer is placed to allow other passive components to be connected together; while providing also a track for probing the devices. Further fabrication details of these two D-H GaAs pHEMTs can be found elsewhere [40].

The two GaN HEMTs are based on an $\mathrm{Al}_{0.253} \mathrm{Ga} 0.747 \mathrm{~N} / \mathrm{GaN}$ heterostructure grown by metal organic chemical vapor deposition (MOCVD) on a 400- $\mu \mathrm{m}$-thick $\mathrm{SiC}$ substrate. The two devices differ in both gate length and width: $0.25 \mu \mathrm{m} \times(2 \times 100) \mu \mathrm{m}$ and $0.15 \mu \mathrm{m} \times(4 \times 50) \mu \mathrm{m}$. The GaN devices were fabricated at the University of Lille, France and further fabrication details can be found elsewhere [41]. 


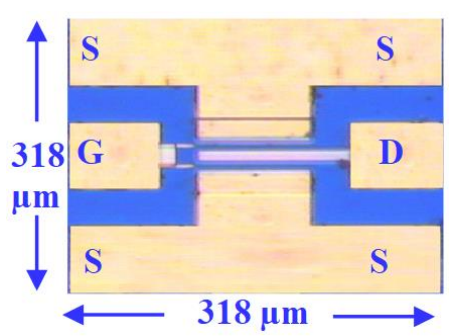

(a)

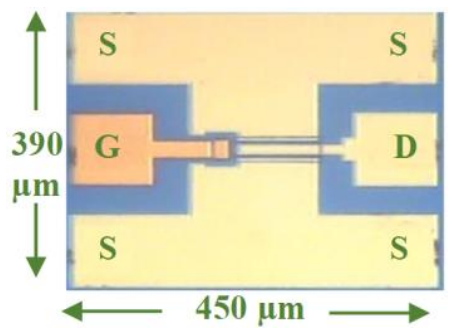

(c)

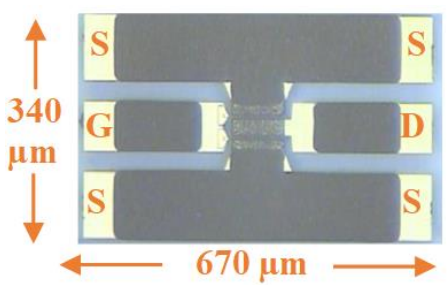

(e)

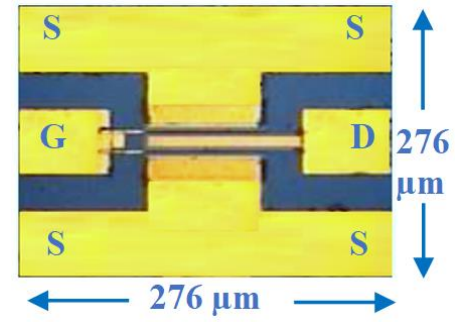

(b)

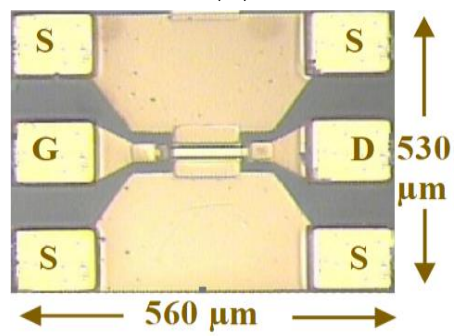

(d)

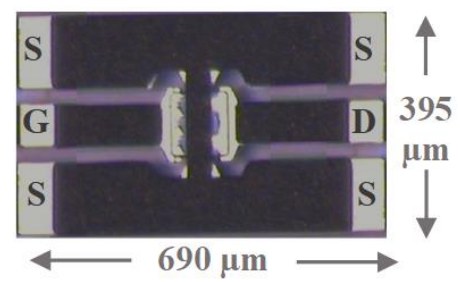

(f)

Figure 1. Photographs of the tested on-wafer devices: (a) $0.5 \mu \mathrm{m} \times(2 \times 100) \mu \mathrm{m}$ S-H GaAs HEMT, (b) $0.5 \mu \mathrm{m} \times$ $(2 \times 75) \mu \mathrm{m}$ S-H GaAs HEMT, (c) $0.5 \mu \mathrm{m} \times(2 \times 100) \mu \mathrm{m}$ virgin D-H GaAs pHEMT, (d) $0.5 \mu \mathrm{m} \times(2 \times 100) \mu \mathrm{m}$ multi-layer D-H GaAs pHEMT, (e) $0.25 \mu \mathrm{m} \times(2 \times 100) \mu \mathrm{m}$ GaN HEMT, and (f) $0.15 \mu \mathrm{m} \times(4 \times 50) \mu \mathrm{m} \mathrm{GaN}$ HEMT.
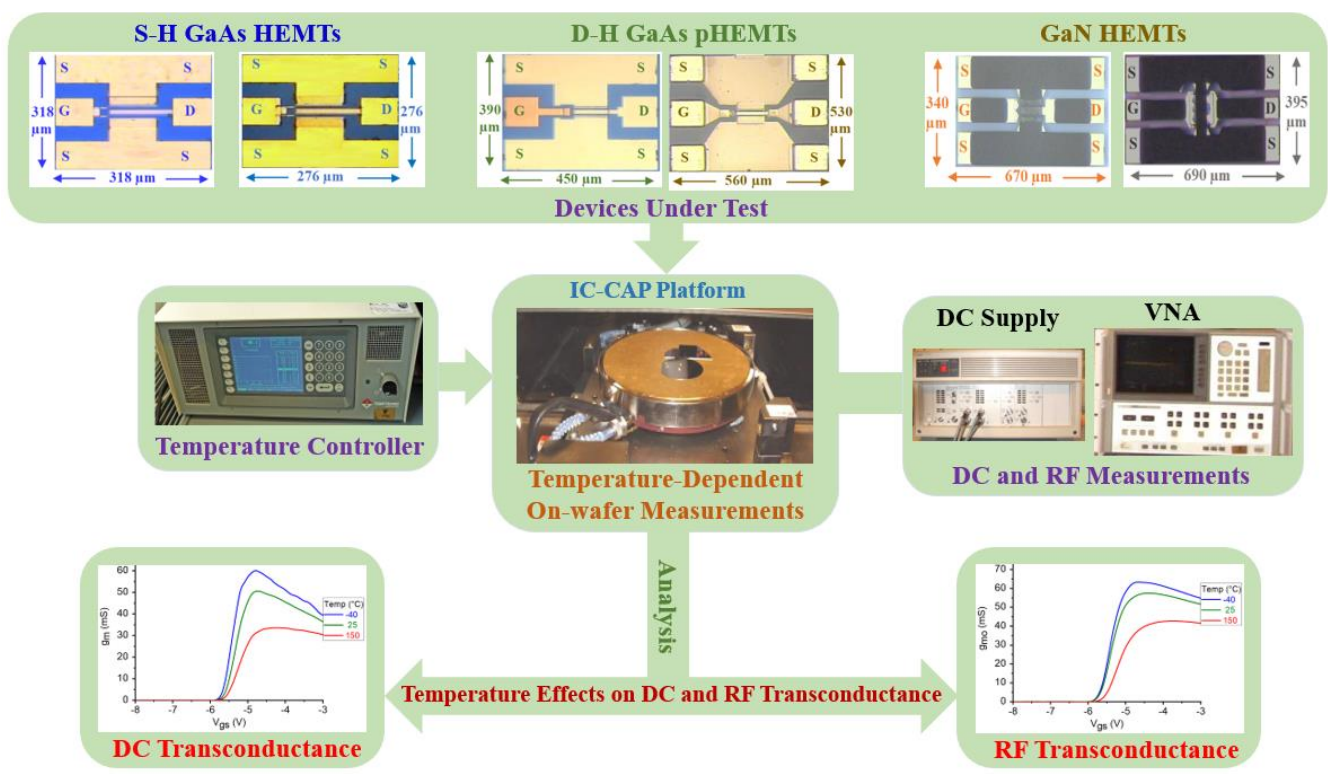

Figure 2. The flow diagram of the temperature-dependent measurement process and investigation of the temperature effects on the DC and RF transconductance for the tested on-wafer HEMT devices. 
Figure 2 illustrates the flow diagram of the temperature-dependent on-wafer measurement process and the subsequent analysis of the impact of the ambient temperature on the DC and RF transconductance. The microwave experiments consist of DC and S-parameters measured from $45 \mathrm{MHz}$ to $50 \mathrm{GHz}$ at $-40^{\circ} \mathrm{C}, 25^{\circ} \mathrm{C}$, and $150^{\circ} \mathrm{C}$. The analysis is performed using the DC characteristics and the Sparameters measured in the saturation region: $\mathrm{V}_{\mathrm{gs}}$ was varied from $-1 \mathrm{~V}$ to $0.8 \mathrm{~V}$ at $\mathrm{Vds}_{\mathrm{ds}}=3 \mathrm{~V}$ for the S-H GaAs HEMTs, $\mathrm{V}_{\mathrm{gs}}$ was varied from $-1.5 \mathrm{~V}$ to $0.6 \mathrm{~V}$ at $\mathrm{V}_{\mathrm{ds}}=3 \mathrm{~V}$ for the D-H GaAs pHEMTs, and $\mathrm{V}_{\mathrm{gs}}$ was varied from $-8 \mathrm{~V}$ to $-3 \mathrm{~V}$ at $\mathrm{V}_{\mathrm{ds}}=15 \mathrm{~V}$ for the GaN HEMTs. The analysis is focused on using the experimental data for developing an accurate study of the DC and RF transconductance.

To ensure that the data were free of human error, the device parameters were measured with a thermal probe station coupled to an HP4142B DC source and an HP8510C vector network analyzer (VNA) by using Keysight's IC-CAP, which is a powerful commercial software for DC and RF semiconductor device characterization and modelling. After the sample reached uniform steady-state temperature, DC and frequency-dependent measurements were carried out at each temperature.

\section{Experimental Results and Discussion}

The DC transconductance at three different ambient temperatures $\left(\mathrm{T}_{\mathrm{a}}=-40^{\circ} \mathrm{C}, 25^{\circ} \mathrm{C}\right.$, and $\left.150^{\circ} \mathrm{C}\right)$ for the studied S-H GaAs HEMTs, D-H GaAs pHEMTs, and GaN HEMTs are given in Figures 3-5, respectively. As can be observed in Figure 3, the DC transconductance of the two studied S-H GaAs HEMTs at $V_{\mathrm{ds}}=3 \mathrm{~V}$ may increase or decrease depending on the selected value of the input voltage. This is due to two temperature-dependent effects contributing in opposite ways to the resultant behavior of the DC transconductance with increasing temperature: the degradation of the electron transport properties and the shift of the threshold voltage $\left(\mathrm{V}_{\mathrm{TH}}\right)$ towards more negative values. The former effect is predominant at higher $\mathrm{V}_{\mathrm{gs}}$, whereas the latter effect is predominant at lower $\mathrm{V}_{\text {gs. }}$. It should be mentioned that the shift of $\mathrm{V}_{\text {тн }}$ can be compensated by the bias circuitry by biasing the device at fixed output voltage and current rather than at fixed output and input voltages [17]. It is worth pointing out that both devices exhibit the zero temperature coefficient point in the DC transconductance behaviour. The two devices show different values of the input voltage for the GZTC point: $V_{g s}=-0.47 \mathrm{~V}$ for $\mathrm{W}=200 \mu \mathrm{m}$ and $\mathrm{V}_{\mathrm{gs}}=$ $0.35 \mathrm{~V}$ for $\mathrm{W}=150 \mu \mathrm{m}$. This result indicates that, by increasing the gate width of the tested devices, the GZTC point shifts towards a more negative value of $\mathrm{V}_{\mathrm{gs}}$. Both devices show a peak in $\mathrm{g}_{\mathrm{m}}$ that decreases with increasing temperature and occurs at about $\mathrm{V}_{\mathrm{gs}}=0.3 \mathrm{~V}$. By selecting the bias condition $\mathrm{V}_{\mathrm{ds}}=3 \mathrm{~V}$ and $\mathrm{V}_{\mathrm{gs}}=0.3 \mathrm{~V}$, we obtain the following values of $\mathrm{g}_{\mathrm{m}}$ for the two devices at the three different ambient temperatures: $35 \mathrm{mS}\left(-40^{\circ} \mathrm{C}\right), 32 \mathrm{mS}\left(25^{\circ} \mathrm{C}\right)$, and $26 \mathrm{mS}\left(150^{\circ} \mathrm{C}\right)$ for the larger-width device (see Figure 3(a)) and $30 \mathrm{mS}\left(-40^{\circ} \mathrm{C}\right), 28.6 \mathrm{mS}\left(25^{\circ} \mathrm{C}\right)$, and $24 \mathrm{mS}\left(150^{\circ} \mathrm{C}\right)$ for the narrower-width device (see Figure 3(b)). As expected, the values of $g_{m}$ are higher for the device with a larger gate width.

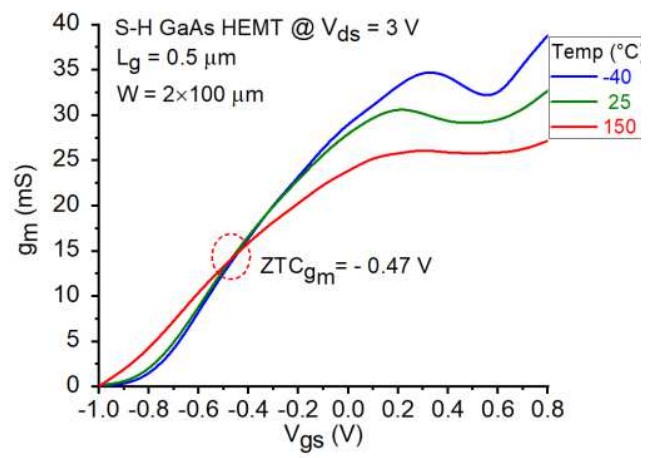

(a)

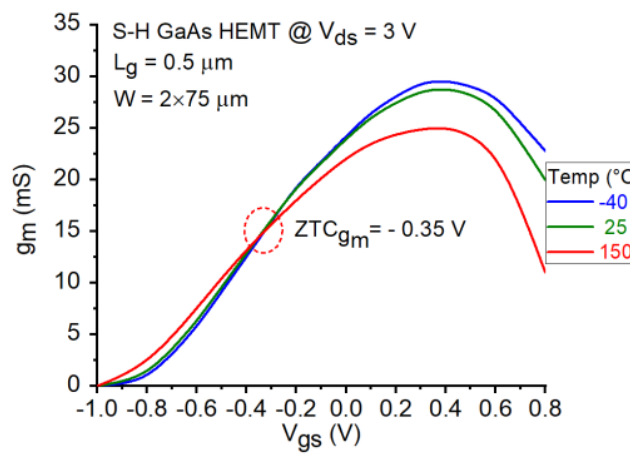

(b)

Figure 3. Behavior of the DC transconductance versus $\mathrm{V}_{\mathrm{gs}}$ for the two studied S-H GaAs HEMTs at $\mathrm{V}_{\mathrm{ds}}=3 \mathrm{~V}$ and $\mathrm{T}=$ $-40^{\circ} \mathrm{C}, 25^{\circ} \mathrm{C}$, and $150^{\circ} \mathrm{C}$ : (a) $0.5 \mu \mathrm{m} \times(2 \times 100) \mu \mathrm{m}$, (b) $0.5 \mu \mathrm{m} \times(2 \times 75) \mu \mathrm{m}$. 


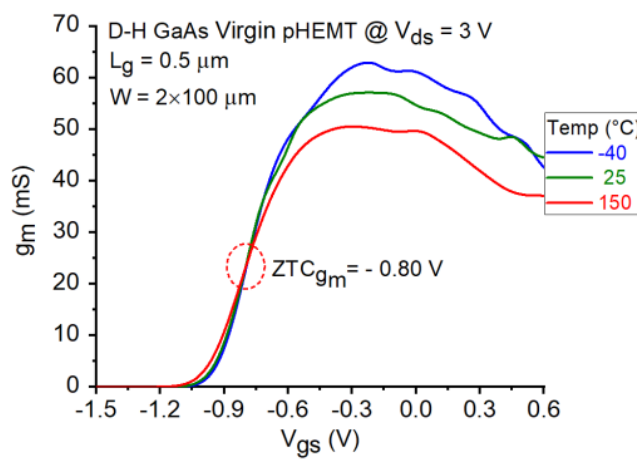

(a)

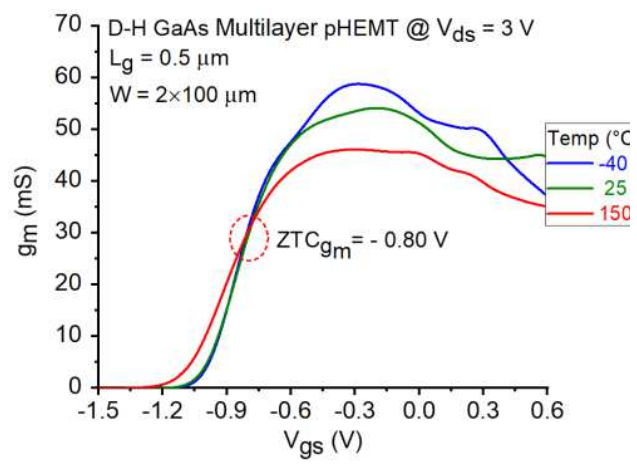

(b)

Figure 4. Behavior of the DC transconductance versus $\mathrm{V}_{\mathrm{gs}}$ for the two studied D-H GaAs pHEMTs at $\mathrm{V}_{\mathrm{ds}}=3 \mathrm{~V}$ and $\mathrm{T}$ $=-40^{\circ} \mathrm{C}, 25^{\circ} \mathrm{C}$, and $150^{\circ} \mathrm{C}$ : (a) virgin: $0.5 \mu \mathrm{m} \times(2 \times 100) \mu \mathrm{m},(\mathrm{b})$ multi-layer: $0.5 \mu \mathrm{m} \times(2 \times 100) \mu \mathrm{m}$.

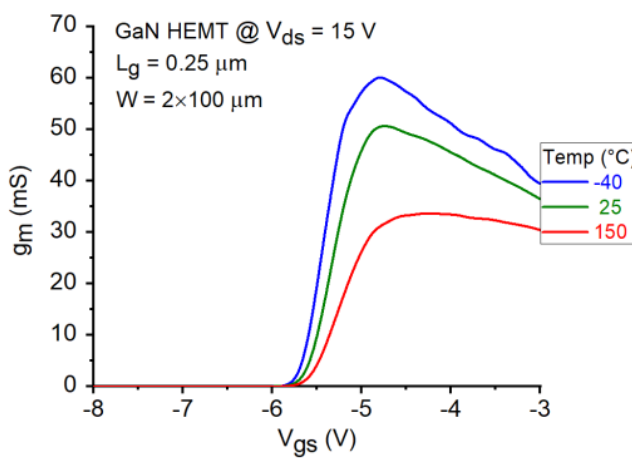

(a)

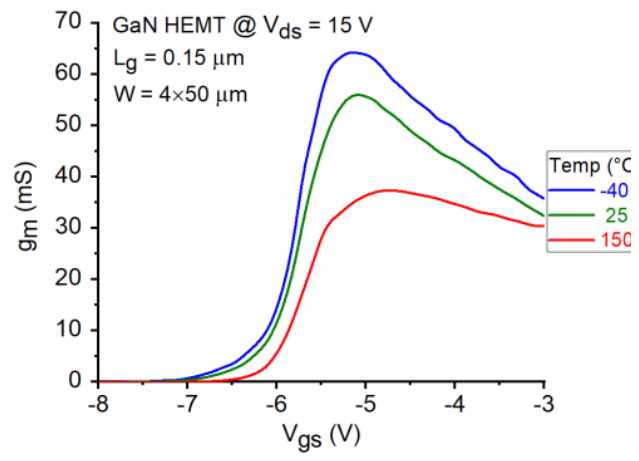

(b)

Figure 5. Behavior of the DC transconductance versus $\mathrm{V}_{\mathrm{gs}}$ for the two studied GaN HEMTs at $\mathrm{V}_{\mathrm{ds}}=15 \mathrm{~V}$ and $\mathrm{T}=-$ $40^{\circ} \mathrm{C}, 25^{\circ} \mathrm{C}$, and $150^{\circ} \mathrm{C}$ : (a) $0.25 \mu \mathrm{m} \times(2 \times 100) \mu \mathrm{m}$, (b) $0.15 \mu \mathrm{m} \times(4 \times 50) \mu \mathrm{m}$.

Similarly to what has been observed for the S-H GaAs HEMTs, the two studied D-H GaAs pHEMTs at $\mathrm{V}_{\mathrm{ds}}=3 \mathrm{~V}$ show a GZTC point in the DC transconductance that is achieved at $\mathrm{V}_{\mathrm{gs}}=-0.8 \mathrm{~V}$ with $\mathrm{V}_{\mathrm{ds}}=3 \mathrm{~V}$ (see Figure 4). This result indicates that the GZTC point is the same for virgin and multi-layer devices and is shifted towards more negative values of $\mathrm{V}_{\mathrm{gs}}$ for the $\mathrm{D}-\mathrm{H}$ GaAs pHEMTs with respect to those observed for the S-H GaAs HEMTs (see Figures 3 and 4). Likewise to the S-H GaAs HEMTs, both virgin and multilayer D-H GaAs pHEMTs show a peak in $\mathrm{g}_{\mathrm{m}}$ that decreases with increasing temperature. This peak occurs at about $\mathrm{V}_{\mathrm{gs}}=-0.3 \mathrm{~V}$. By selecting the bias condition of $\mathrm{V}_{\mathrm{ds}}=3 \mathrm{~V}$ and $\mathrm{V}_{\mathrm{gs}}=-0.3 \mathrm{~V}$, we obtain the following values of $\mathrm{g}_{\mathrm{m}}$ for the two devices at the three different ambient temperatures: $63 \mathrm{mS}\left(-40^{\circ} \mathrm{C}\right), 57 \mathrm{mS}\left(25^{\circ} \mathrm{C}\right)$, and $50 \mathrm{mS}\left(150^{\circ} \mathrm{C}\right)$ for the virgin device and $59 \mathrm{mS}\left(-40^{\circ} \mathrm{C}\right), 54 \mathrm{mS}\left(25^{\circ} \mathrm{C}\right)$, and $46 \mathrm{mS}\left(150^{\circ} \mathrm{C}\right)$ for the multilayer device. This denotes that $\mathrm{g}_{\mathrm{m}}$ is slightly reduced after using the multilayer 3-D MMIC technology [42].

Figure 5 shows that, in case of the two studied GaN HEMTs, the DC transconductance is significantly degraded with rising temperature, due to the degradation of the carrier transport characteristics that is predominant temperature-dependent effect. The two devices show a peak in $\mathrm{g}_{\mathrm{m}}$ that decreases with increasing temperature and occurs at about $V_{g s}=-4.8 \mathrm{~V}$. By selecting the bias condition $V_{d s}=15 V_{\text {and }} V_{g s}$ $=-4.8 \mathrm{~V}$, we obtain the following values of $\mathrm{g}_{\mathrm{m}}$ for the two devices at the three different ambient temperatures: $59 \mathrm{mS}\left(-40^{\circ} \mathrm{C}\right), 51 \mathrm{mS}\left(25^{\circ} \mathrm{C}\right)$, and $33 \mathrm{mS}\left(150^{\circ} \mathrm{C}\right)$ for the longer device and $61 \mathrm{mS}\left(-40^{\circ} \mathrm{C}\right), 53$ $\mathrm{mS}\left(25^{\circ} \mathrm{C}\right)$, and $38 \mathrm{mS}\left(150^{\circ} \mathrm{C}\right)$ for the shorter device. As expected, the values of $\mathrm{g}_{\mathrm{m}}$ are higher for the device with a shorter gate length. 
At frequencies low enough to neglect the reactive components, $\mathrm{Y}_{21}$ can be defined in terms of the equivalent-circuit parameters (ECPs) (see Fig. 6) as follows [43]:

$$
Y_{21}=\frac{g_{m o}}{1+g_{m o} R_{s}+\frac{R_{s}+R_{d}}{R_{d s}}}
$$

This equation shows that the RF transconductance can be estimated as the low-frequency $Y_{21}$, which should be purely real and correspond to the DC transconductance when the low-frequency dispersion effects are negligible. To develop the present analysis, we consider only the real part of the measured $\mathrm{Y}_{21}$ that is evaluated at $45 \mathrm{MHz}$, which is the lowest frequency point of our measurements.

Figures 7-9 reports the impact of the temperature on the performance of the six studied devices by focusing on $\operatorname{Re}\left(\mathrm{Y}_{21}\right)$ at $45 \mathrm{MHz}$. Similarly to what has been observed for the DC transconductance, the low-frequency $\operatorname{Re}\left(\mathrm{Y}_{21}\right)$ also exhibits the GZTC point in case of the GaAs HEMTs and pHEMTs (see Figures 7 and 8), whereas the low-frequency $\operatorname{Re}\left(\mathrm{Y}_{21}\right)$ gets degraded for all $\mathrm{V}_{\mathrm{gs}}$ values by increasing the temperature in case of the GaN HEMTs (see Figure 9).

The equivalent-circuit model in Figure 6 was used to represent the measured S-parameters of the six studied devices. The ECPs were obtained using the well-known "cold" pinch-off methods, which has been widely and successfully applied to HEMT technology in recent years [44-50]. The intrinsic RF transconductance values are then extracted at the "hot" bias conditions of interest. The achieved values of the intrinsic RF transconductance for the six studied devices are presented in Figures 10-12. Similarly to what has been observed for the DC and RF transconductance (see Figures 3-5 and 7-9), the intrinsic RF transconductance also exhibits the GZTC point in case of the GaAs HEMTs and pHEMTs (see Figures 10 and 11), whereas the intrinsic $R F g_{m}$ gets degraded for all $V_{g s}$ values by increasing the temperature in case of the GaN HEMTs (see Figure 12). Table 1 shows that, by considering a fixed bias point, the intrinsic RF $\mathrm{g}_{\mathrm{m}}$ for the studied devices is found to be greater than the $\operatorname{Re}\left(\mathrm{Y}_{21}\right)$ at $45 \mathrm{MHz}$ and $\mathrm{g}_{\mathrm{m}}$, which is due to the impact of the extrinsic resistances (see equation (1)).

Table II reports the values of $\mathrm{V}_{\text {gsGZTC, }}$ which is the gate-source voltage at which the transconductance is temperature insensitive, for the four studied S-H GaAs HEMTs and D-H GaAs pHEMTs at Vds $=3 \mathrm{~V}$. The achieved values of $\mathrm{V}_{\mathrm{gs} G \mathrm{ZTC}}$ are roughly the same by using $\mathrm{g}_{\mathrm{m}}, \operatorname{Re}\left(\mathrm{Y}_{21}\right)$ at $45 \mathrm{MHz}$, and $\mathrm{g}_{\mathrm{m} o}$.

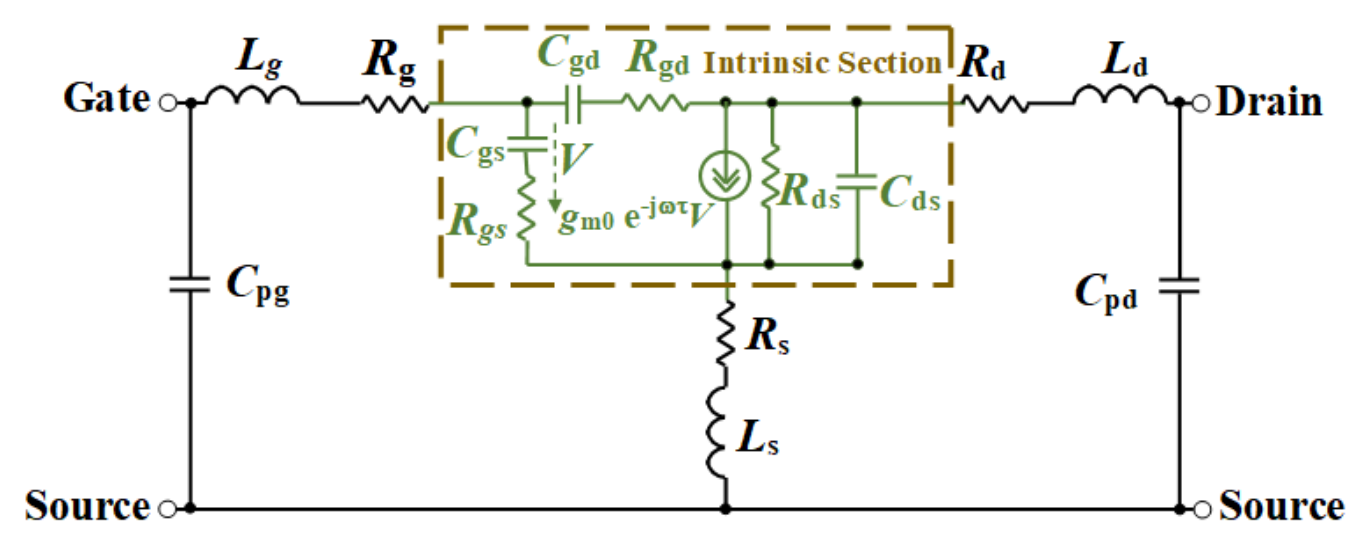

Figure 6. Equivalent-circuit model for the studied HEMTs. 


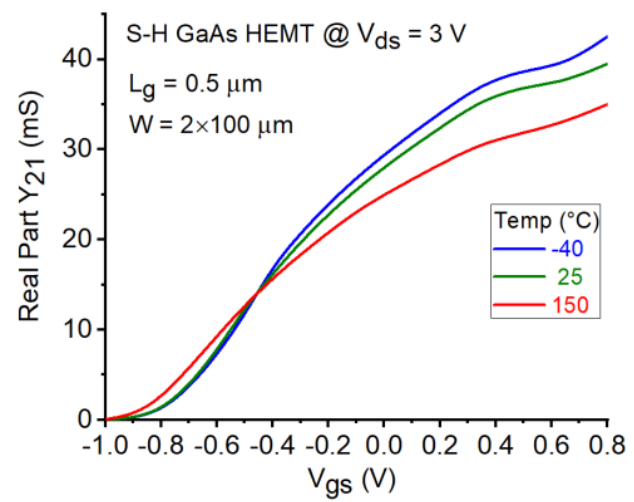

(a)

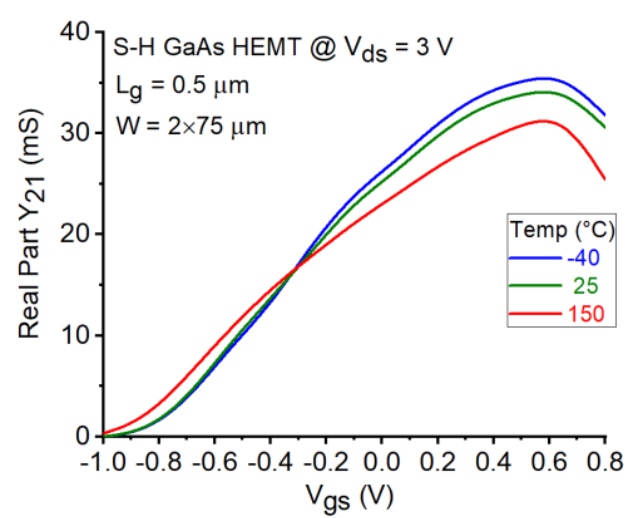

(b)

Figure 7. Behavior of the real part of $\mathrm{Y}_{21}$ at $45 \mathrm{MHz}$ versus $\mathrm{V}_{\mathrm{gs}}$ for the two studied S-H GaAs HEMTs at $\mathrm{V}_{\mathrm{ds}}=3 \mathrm{~V}$ and $\mathrm{T}=-40^{\circ} \mathrm{C}, 25^{\circ} \mathrm{C}$, and $150^{\circ} \mathrm{C}:(\mathrm{a}) 0.5 \mu \mathrm{m} \times(2 \times 100) \mu \mathrm{m}$, (b) $0.5 \mu \mathrm{m} \times(2 \times 75) \mu \mathrm{m}$.

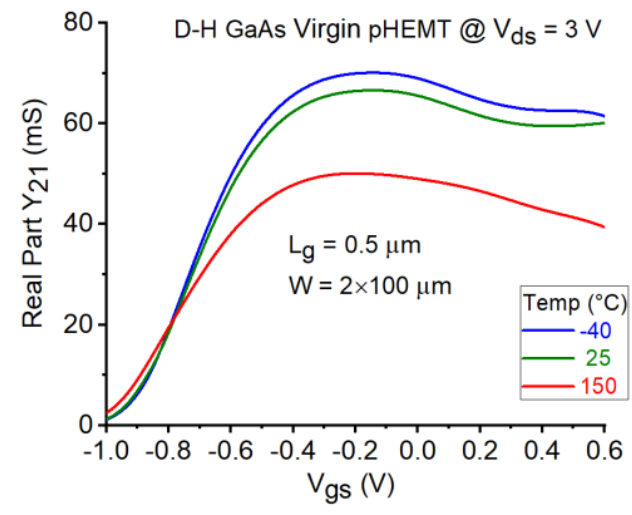

(a)

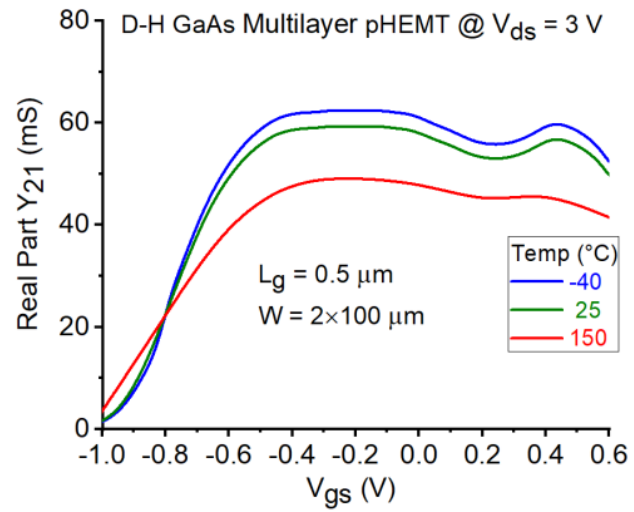

(b)

Figure 8. Behavior of the real part of $\mathrm{Y}_{21}$ at $45 \mathrm{MHz}$ versus $\mathrm{V}_{\mathrm{gs}}$ for the two studied $\mathrm{D}-\mathrm{H}$ GaAs pHEMTs at $\mathrm{V}_{\mathrm{ds}}=3 \mathrm{~V}$ and $\mathrm{T}=-40^{\circ} \mathrm{C}, 25^{\circ} \mathrm{C}$, and $150^{\circ} \mathrm{C}$ : (a) Virgin: $0.5 \mu \mathrm{m} \times(2 \times 100) \mu \mathrm{m}$, (b) multi-layer: $0.5 \mu \mathrm{m} \times(2 \times 100) \mu \mathrm{m}$.

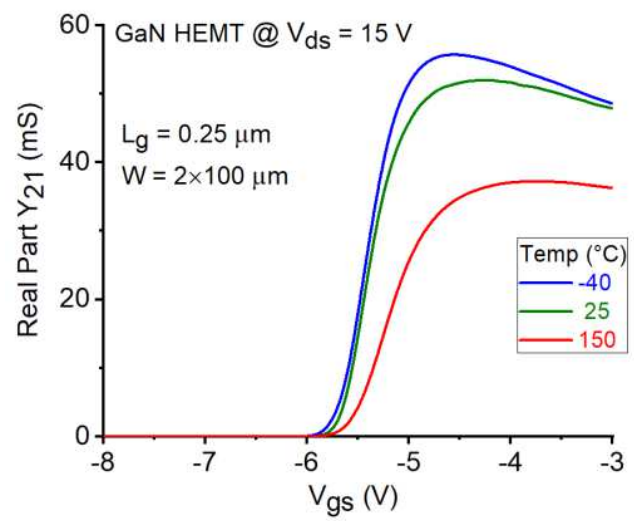

(a)

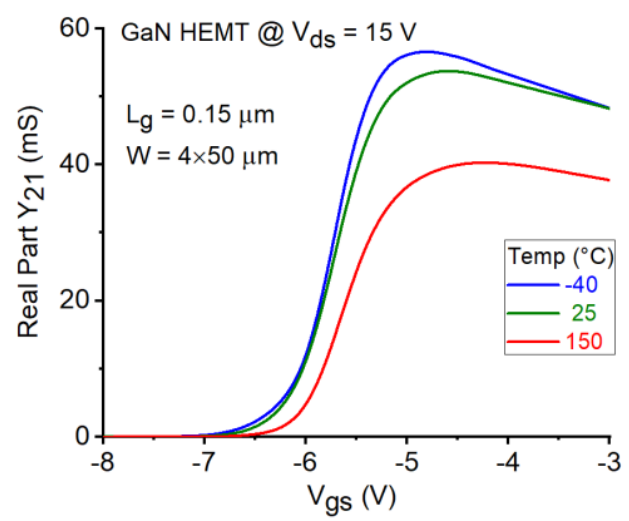

(b)

Figure 9. Behavior of the real part of $\mathrm{Y}_{21}$ at $45 \mathrm{MHz}$ versus $\mathrm{V}_{\mathrm{gs}}$ for the two studied GaN HEMTs at $\mathrm{V}_{\mathrm{ds}}=15 \mathrm{~V}$ and $\mathrm{T}=$ $-40^{\circ} \mathrm{C}, 25^{\circ} \mathrm{C}$, and $150^{\circ} \mathrm{C}$ : (a) $0.25 \mu \mathrm{m} \times(2 \times 100) \mu \mathrm{m}$, (b) $0.15 \mu \mathrm{m} \times(4 \times 50) \mu \mathrm{m}$. 


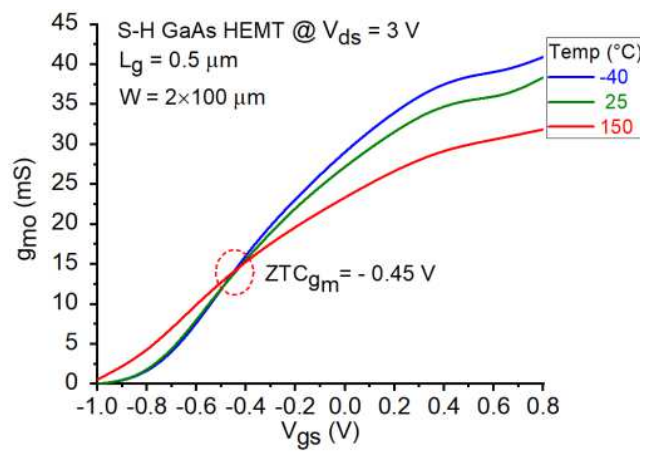

(a)

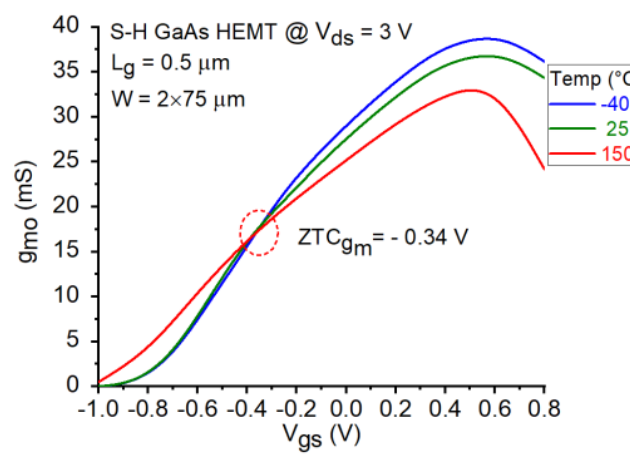

(b)

Figure 10. Behavior of the intrinsic RF transconductance versus $\mathrm{V}_{\mathrm{gs}}$ for the two studied S-H GaAs HEMTs at $\mathrm{V}_{\mathrm{ds}}=3$ $\mathrm{V}$ and $\mathrm{T}=-40^{\circ} \mathrm{C}, 25^{\circ} \mathrm{C}$, and $150^{\circ} \mathrm{C}$ : (a) $0.5 \mu \mathrm{m} \times(2 \times 100) \mu \mathrm{m}$, (b) $0.5 \mu \mathrm{m} \times(2 \times 75) \mu \mathrm{m}$.

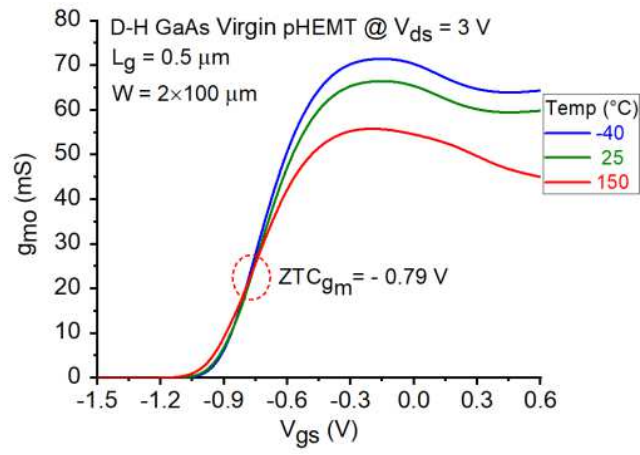

(a)

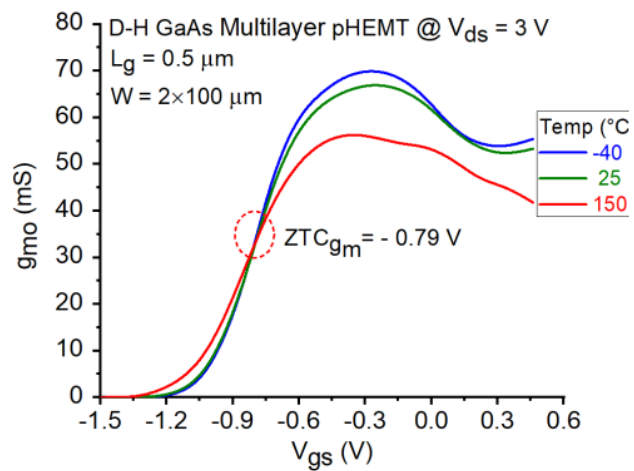

(b)

Figure 11. Behavior of the intrinsic RF transconductance versus $V_{g s}$ for the two studied D-H GaAs pHEMTs at $V_{d s}=$ $3 \mathrm{~V}$ versus $\mathrm{V}_{\mathrm{gs}}$ under different temperature conditions: (a) Virgin: $0.5 \mu \mathrm{m} \times(2 \times 100) \mu \mathrm{m}$, (b) multi-layer: $0.5 \mu \mathrm{m} \times(2 \times$ 100) $\mu \mathrm{m}$.

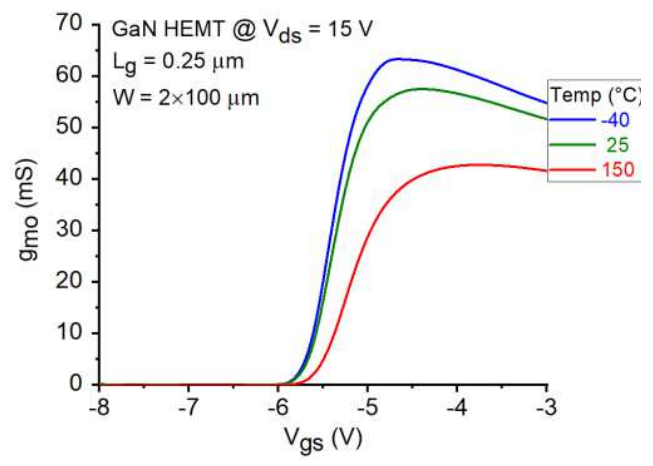

(a)

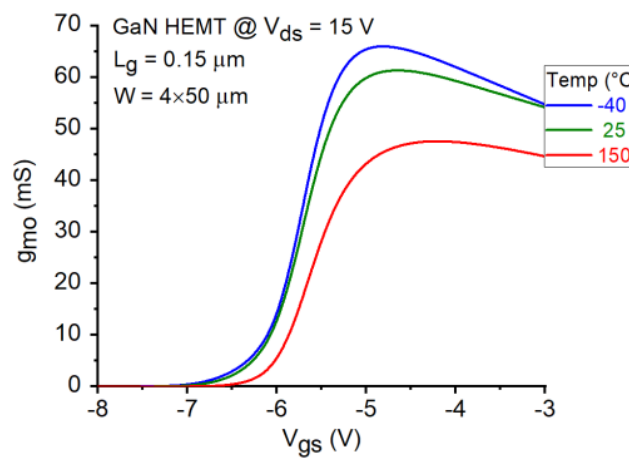

(b)

Figure 12. Behavior of the intrinsic RF transconductance versus $V_{\mathrm{gs}}$ for the two studied GaN HEMTs at $\mathrm{V}_{\mathrm{ds}}=15 \mathrm{~V}$ and $\mathrm{T}=-40^{\circ} \mathrm{C}, 25^{\circ} \mathrm{C}$, and $150^{\circ} \mathrm{C}:(\mathrm{a}) 0.25 \mu \mathrm{m} \times(2 \times 100) \mu \mathrm{m},(\mathrm{b}) 0.15 \mu \mathrm{m} \times(4 \times 50) \mu \mathrm{m}$. 
Table 1. DC and RF transconductance for the six studied HEMTs at a selected bias condition.

\begin{tabular}{ccccc}
\hline HEMTs & $\begin{array}{c}\mathrm{T}_{\mathrm{a}} \\
\left({ }^{\circ} \mathrm{C}\right)\end{array}$ & $\mathrm{g}_{\mathrm{m}}(\mathrm{mS})$ & $\operatorname{Re}\left(\mathrm{Y}_{21}\right)(\mathrm{mS}) @ 45 \mathrm{MHz}$ & $\mathrm{g}_{\mathrm{mo}}(\mathrm{mS})$ \\
\hline S-H GaAs HEMT & -40 & 35 & 36 & 38 \\
$0.5 \times 200 \mu \mathrm{m}^{2}$ & 25 & 32 & 34 & 35 \\
@ $\mathrm{V}_{\mathrm{ds}}=3 \mathrm{~V}$ and $\mathrm{V}_{\mathrm{gs}}=0.3 \mathrm{~V}$ & -150 & 26 & 29 & 30 \\
S-H GaAs HEMT & -40 & 30 & 32 & 34 \\
$0.5 \times 150 \mu \mathrm{m}^{2}$ & 25 & 28.6 & 30 & 32 \\
@ $\mathrm{V}_{\mathrm{ds}}=3 \mathrm{~V}$ and $\mathrm{V}_{\mathrm{gs}}=0.3 \mathrm{~V}$ & -150 & 24 & 26 & 29 \\
Virgin D-H GaAs pHEMT & -40 & 63 & 68 & 70 \\
$0.5 \times 200 \mu \mathrm{m}^{2}$ & 25 & 57 & 61 & 63 \\
@ $\mathrm{V}_{\mathrm{ds}}=3 \mathrm{~V}$ and $\mathrm{V}_{\mathrm{gs}}=-0.3 \mathrm{~V}$ & -150 & 50 & 51 & 53 \\
Multi-layer D-H GaAs pHEMT & -40 & 59 & 62 & 65 \\
$0.5 \times 200 \mu \mathrm{m}^{2}$ & 25 & 54 & 59 & 61 \\
@ $\mathrm{V}_{\mathrm{ds}}=3 \mathrm{~V}$ and $\mathrm{V}_{\mathrm{gs}}=-0.3 \mathrm{~V}$ & -150 & 46 & 49 & 51 \\
GaN HEMT & -40 & 59 & 55 & 64 \\
$0.25 \times 200 \mu \mathrm{m}^{2}$ & 25 & 51 & 50 & 56 \\
@ $\mathrm{V}_{\mathrm{ds}}=15 \mathrm{~V}$ and $\mathrm{V}_{\mathrm{gs}}=-4.8 \mathrm{~V}$ & -150 & 33 & 31 & 37 \\
GaN HEMT & -40 & 61 & 57 & 68 \\
$0.15 \times 200 \mu \mathrm{mm}^{2}$ & 25 & 53 & 54 & 44 \\
\hline $\mathrm{V}_{\mathrm{ds}}=15 \mathrm{~V}$ and $\mathrm{V}_{\mathrm{gs}}=-4.8 \mathrm{~V}$ & -150 & 38 & 39 & \\
\hline
\end{tabular}

Table 2. Values of the gate-source voltage at which the transconductance is temperature insensitive for the four studied S-H GaAs HEMTs and D-H GaAs pHEMTs at a drain-source voltage of $3 \mathrm{~V}$.

\begin{tabular}{|c|c|c|c|}
\hline HEMTs & $\begin{array}{c}\mathrm{V}_{\text {gsGZTC }}(\mathrm{V}) \\
\text { based on } \\
\mathrm{g}_{\mathrm{m}}\end{array}$ & $\begin{array}{c}\mathrm{V}_{\mathrm{gsGZTC}}(\mathrm{V}) \\
\text { based on } \operatorname{Re}\left(\mathrm{Y}_{21}\right) @ 45 \mathrm{MHz}\end{array}$ & $\begin{array}{l}\mathrm{V}_{\mathrm{gsGZTC}}(\mathrm{V}) \\
\text { based on } \mathrm{gmo}_{\mathrm{mo}}\end{array}$ \\
\hline $\begin{array}{l}\text { S-H GaAs HEMT } \\
0.5 \times 200 \mu \mathrm{m}^{2}\end{array}$ & -0.47 & -0.45 & -0.45 \\
\hline $\begin{array}{c}\text { S-H GaAs HEMT } \\
0.5 \times 150 \mu \mathrm{m}^{2}\end{array}$ & -0.35 & -0.34 & -0.34 \\
\hline $\begin{array}{c}\text { Virgin D-H GaAs pHEMT } \\
0.5 \times 200 \mu \mathrm{m}^{2}\end{array}$ & -0.80 & -0.79 & -0.79 \\
\hline $\begin{array}{l}\text { Multi-layer D-H GaAs pHEMT } \\
0.5 \times 200 \mu \mathrm{m}^{2}\end{array}$ & -0.80 & 0.79 & 0.79 \\
\hline
\end{tabular}

\section{Conclusion}

To gain a comprehensive overview of the temperature effects on the HEMT performance, an experimental study was developed focusing on the behavior of both DC and RF transconductance for various HEMT devices in high- and low-temperature conditions. It was shown that the temperature effects can strongly depend on the chosen device technology and selected bias condition. However, in GaAs-based devices, an operating bias condition at which the DC and RF transconductance are temperature insensitive can be defined, as a result of two-opposite temperature-dependent effects 
counteracting with each other: the degradation of the electron transport properties and the shift of the threshold voltage towards more negative values. On the other hand, the GaN-based devices show a significant reduction of both DC and RF transconductance at higher temperatures for all studied values of the gate-source voltage, as a result of the degradation of the electron transport properties that is the predominant temperature-dependent effect.

\section{References}

1. Ayubi-Moak, J.S., Akis, R., Ferry, D.K. et al. Towards the global modeling of InGaAs-based pseudomorphic HEMTs. J Comput Electron 7, 187-191 (2008).

2. Delagebeaudeuf, D.; Delescluse, P.; Etienne, P.; Laviron, M.; Chaplart, J.; Linh, N. T. Two-dimensional electron gas MESFET structure. Electron. Lett. 1980, 116, 667-668.

3. Rohdin, H.; Lee, G.S. Interfacial gate resistance in schottky-barrier-gate field-effect transistors. IEEE Trans. Electron Dev. 1998, 45, 2407-2416.

4. Resca, D.; Raffo, A.; Santarelli, A.; Vannini, G.; Filicori, F. Scalable equivalent circuit FET model for MMIC design identified through FW-EM analyses. IEEE Trans. Microw. Theory Techn. 2009, 57, 245-253.

5. Crupi, G.; Raffo, A.; Vadalà, V.; Vannini, G.; Schreurs, D.M.M.-P.; Caddemi, A. Scalability of multifinger HEMT performance. IEEE Microw. Wirel. Compon. Lett. 2020, 30, 869-872.

6. Vo, V.T.; Krishnamurthy, L.; Sun, Q.; Rezazadeh, A.A. 3-D low-loss coplanar waveguide transmission lines in multilayer MMICs. IEEE Trans. Microw. Theory Techn. 2006, 54, 2864-2871.

7. Toscano, A., Vegni, L. Advanced Electromagnetic Modelling of Multilayer Monolithic Microwave Integrated Circuit. Journal of Computational Electronics 2, 469-473 (2003).

8. Alim, M.A.; Rezazadeh, A.A. Uniformity investigation of pHEMTs small-signal parameters for pre and post multilayer fabrication in 3D MMICs. Semicond Sci Technol. 2020, 35, 015013.

9. Belache, A.; Vanoverschelde, A.; Salmer, G.; Wolny, M. Experimental analysis of HEMT behavior under lowtemperature conditions. IEEE Trans. Electron Dev. 1991, 38, 3-13.

10. Anholt, R.E.; Swirhun, S.E. Experimental investigation of the temperature dependence of GaAs FET equivalent circuits. IEEE Trans. Electron Dev. 1992, 39, 2029-2036.

11. Marinkovic, Z.; Markovic, V. Temperature-dependent models of low-noise microwave transistors based on neural networks. Int. J. RF Microw. Comput. Aided Eng. 2005, 15, 567-577.

12. Caddemi, A.; Crupi, G.; Donato, N. Temperature effects on DC and small signal RF performance of AlGaAs/GaAs HEMTs. Microelectron. Reliab. 2006, 46, 169-173.

13. Huang, J.C.; Hsu, W.C.; Lee, C.S.; Huang, D.H.; Huang, M.F. Temperature-dependent characteristics of enhancement-/depletion-mode double $\delta$-doped AlGaAs/InGaAs pHEMTs and their monolithic DCFL integrations. Solid State Electron. 2007, 51, 882-887.

14. Alim, M.A.; Rezazadeh, A.A. Temperature-dependent DC and small-signal analysis of AlGaAs/InGaAs pHEMT for high frequency applications. IEEE Trans. Electron Dev. 2016, 63, 1005-1012.

15. Moschetti, G.; et al. Stability investigation of large gate-width metamorphic high electron-mobility transistors at cryogenic temperature. IEEE Trans Microw Theory Techn. 2016; 64, 3139-3150.

16. Zhu, Y.-Y.; Ma, J.-G. ; Fu, H.-P. ; Zhang, Q.-J. ; Cheng, Q.-F. ; Lin, Q. Accurate modeling of pHEMT output current derivatives over a wide temperature range. Int. J. Numer. Model. Electron. Netw. Dev. Field 2017, 30, e2185.

17. Alim, M.A.; Rezazadeh, A.A.; Crupi, G. Experimental insight into the temperature effects on DC and microwave characteristics for a GaAs pHEMT in multilayer 3-D MMIC technology. Int. J. RF Microw. Comput. Aided Eng. 2020, 30, e22379.

18. Alim, M. A.; Chowdhury, A. Z.; Islam, S.; Gaquiere, C.; Crupi, G. Temperature-sensitivity of two microwave HEMT devices: AlGaAs/GaAs vs AlGaN/GaN heterostructures. Electronics 2021, 10, 1115.

19. Nuttinck, S.; Gebara, E.; Laskar, J.; Harris, H.M. Study of self-heating effects, temperature-dependent modeling, and pulsed load-pull measurements on GaN HEMTs. IEEE Trans. Microw. Theory Techn. 2001, 49, 2413-20.

20. Thorsell, M.; Andersson, K.; Fagerlind, M.; Südow, M.; Nilsson, P.-A.; Rorsman, N. Thermal study of the highfrequency noise in GaN HEMTs. IEEE Trans. Microw. Theory Techn. 2009, 57, 19-26.

21. Darwish, A. M.; Huebschman, B. D.; Viveiros, E.; Hung, H. A. Dependence of GaN HEMT millimeter-wave performance on temperature. IEEE Trans. Microw. Theory Techn. 2009, 57, 3205-3211.

22. Marinković, Z.; et al., Neural approach for temperature dependent modeling of GaN HEMTs. Int. J. Numer. Model. Electron. Netw. Dev. Field 2015, 28, 359-370.

23. Crupi, G.; Raffo, A.; Avolio, G.; Schreurs, D.M.M.-P.; Vannini, G.; Caddemi, A. Temperature influence on GaN HEMT equivalent circuit. IEEE Microw. Wireless Comp. Lett. 2016, 26, 813-815. 
24. Crupi, G.; Raffo, A.; Vadalà, V.; Vannini, G.; Caddemi, A. A new study on the temperature and bias dependence of the kink effects in $S_{22}$ and $h_{21}$ for the GaN HEMT technology. Electronics 2018, 7, 353.

25. Crupi, G.; Raffo, A.; Vadalà, V.; Vannini, G.; Caddemi, A. High-periphery GaN HEMT modeling up to 65 GHz and $200^{\circ} \mathrm{C}$. Solid-State Electron. 2019, 152, 11-16.

26. Chen, Y.; et al. Temperature-dependent small signal performance of GaN-on-diamond HEMTs. Int. J. Numer. Model. Electron. Netw. Dev. Field 2020, 33, e2620.

27. Majumdar, A.; Chatterjee, S.; Chatterjee, S.; Chaudhari, S.S.; Poddar D.R. An ambient temperature dependent small signal model of GaN HEMT using method of curve fitting. Int. J. RF Microw. Comput.-Aided Eng. 2020, 30, e22434.

28. Jarndal, A.H., Muhaureq, S. A particle swarm neural networks electrothermal modeling approach applied to GaN HEMTs. J Comput Electron 18, 1272-1279 (2019).

29. Luo, H.; Zhong, Z.; Hu, W.; Guo, Y. Analysis and modeling of the temperature-dependent nonlinearity of intrinsic capacitances in AlGaN/GaN HEMTs. IEEE Microw. Wireless Comp. Lett. 2021, 31, 373-376.

30. Jarndal, A.; Alim, M.A.; Raffo, A.; Crupi, G. 2-mm-gate-periphery GaN high electron mobility transistors on SiC and Si substrates: A comparative analysis from a small-signal standpoint. Int. J. RF Microw. Comput.-Aided Eng. 2021, 31, e22642.

31. Alim, M. A.; Gaquiere, C.; Crupi, G. An experimental and systematic insight into the temperature sensitivity for a 0.15- $\mu \mathrm{m}$ gate-length HEMT based on the GaN technology. Micromachines 2021, 12, 549 .

32. Pospieszalski, M.W. Extremely low-noise amplification with cryogenic FETs and HFETs: 1970-2004. IEEE Microw.Mag. 2005, 6, 62-75.

33. Colangeli, S.; Bentini, A.; Ciccognani, W.; Limiti, E.; Nanni, A. GaN-based robust low-noise amplifiers. IEEE Trans. Electron Dev. 2013, 60, 3238-3248.

34. Nalli, A.; Raffo, A.; Crupi, G.; D'Angelo, S.; Resca, D.; Scappaviva, F.; Salvo, G.; Caddemi, A.; Vannini, G. GaN HEMT noise model based on electromagnetic simulations. IEEE Trans. Microw. Theory Tech. 2015, 63, $2498-2508$.

35. Crupi, G.; Vadalà, V.; Colantonio, P.; Cipriani, E.; Caddemi, A.; Vannini, G.; Schreurs, D.M.M.-P. Empowering GaN HEMT models: The gateway for power amplifier design. Int. J. Numer. Model. Electron. Netw. Dev. Field 2017, $30, \mathrm{e} 2125$.

36. Resca, D.; Raffo, A.; Di Falco, S.; Scappaviva, F.; Vadalà, V.; Vannini, G. X-band GaN power amplifier for future generation SAR systems. IEEE Microw. Wirel. Compon. Lett. 2014, 24, 266-268.

37. Giofrè, R.; Colantonio, P.; Costanzo, F.; Vitobello, F.; Lopez, M.; Cabria, L. A 17.3-20.2-GHz GaN-Si MMIC balanced HPA for very high throughput satellites. IEEE Microw. Wireless Comp. Lett. 2021, 31, $296-299$.

38. Ramella, C.; Camarchia, V.; Piacibello, A.; Pirola, M.; Quaglia, R. Watt-Level 21-25-GHz integrated Doherty power amplifier in GaAs technology. IEEE Microw. Wirel. Compon. Lett. 2021, 31, 505-508.

39. Alim, M.A.; Rezazadeh, A.A. Study of third-order intercepts and nonlinear distortion level for S-H GaAs HEMTs. Semicond. Sci. Technol. 2020, 35, 085001.

40. Alim, M.A.; Rezazadeh, A.A. Third-order intercepts and nonlinear distortion level investigation for pre and post multilayer pHEMTs. Solid State Electron. 2020, 169, 107809.

41. Alim, M.A.; Rezazadeh, A.A.; Gaquiere, C. Thermal characterization of DC and small-signal parameters of 150 $\mathrm{nm}$ and $250 \mathrm{~nm}$ gate-length AlGaN/GaN HEMTs grown on a SiC substrate. Semicond Sci Technol. 2015, 30, 125005.

42. Alim, M.A.; Mayahsa, M. A.; Haris, N.; Kyabaggu, P.B. K.; Rezazadeh, A.A. “Device considerations and characterizations of pre and post fabricated GaAs based pHEMTs using multilayer 3-D MMIC technology," Semicond. Sci. Technol. 2017, 32, 055003.

43. Crupi, G.; Raffo, Marinković, Z.; Avolio, G.; Caddemi, A.; Marković, V.; Vannini, G.; Schreurs, D. M. M.-P. An extensive experimental analysis of the kink effects in $\mathrm{S}_{22}$ and $\mathrm{h}_{21}$ for a GaN HEMT IEEE Trans. Microw. Theory Techn. 2014, 62, 513-520.

44. Caddemi, A.; Crupi, G.; Donato, N. A robust and fast procedure for the determination of the small signal equivalent circuit of HEMTs. Microelectronics Journal 2004, 35, 431-436.

45. Arivazhagan, L., Jarndal, A. \& Nirmal, D. GaN HEMT on Si substrate with diamond heat spreader for high power applications. J Comput Electron 20, 873-882 (2021).

46. Crupi, G.; Schreurs, D.M.M.-P.; Raffo, A.; Caddemi, A.; Vannini, G. A new millimeter wave small-signal modeling approach for pHEMTs accounting for the output conductance time delay. IEEE Trans. Microw. Theory Techn. 2008, 56, 741-746.

47. Alim, M. A.; Rezazadeh, A. A.; Gaquiere, C. Temperature effect on DC and equivalent circuit parameters of 0.15$\mu \mathrm{m}$ gate length GaN/SiC HEMT for microwave applications. IEEE Trans. Microw. Theory Techn. 2016, 64, 34833491. 
48. Al Sabbagh, M.; Yagoub, M.C.E.; Park, J. New small-signal extraction method applied to GaN HEMTs on different substrates. Int. J. R. F. Microw. Comput. Aided Eng. 2020, 30, e22291.

49. Chen, Y.; Xu, Y.; Luo, Y.;Wang, C.;Wen, Z.; Yan, B.; Xu, R. A reliable and efficient small-signal parameter extraction method for GaN HEMTs. Int. J. Numer. Model. Electron. Netw. Dev. Field 2020, 33, e2540.

50. Du, X.; Helaoui, M.; Cai, J.; Liu, J.; Ghannouchi, F.M. Improved small-signal hybrid parameter-extraction technique for AlGaN/GaN high electron mobility transistors. Int. J. RF Microw. Comput. Aided Eng. 2021, 31, e22562. 